\title{
Genetic Algorithm-Optimized PID Controller for better Performance of PV System
}

\author{
Roshdy Abdelrassoul, \\ SM, IEEE
}

Yosra Ali

\author{
Mohamed Saad Zaghloul
}

Arab Academy for Science and Technology, Alexandria, Egypt

\begin{abstract}
In recent years, a radical increase of photovoltaic (PV) power generators installation took place because of increased efficiency of solar cells, as well as the growth of manufacturing technology of solar panels. This paper shows the operation and modeling of photovoltaic systems, particularly designing PID controller to control the system. Parameters of the designed controller are tuned using genetic algorithm (GA) which leads to getting the best performance of the designed PV system. Using GA the maximum overshoot and rise time obtained become $0.1 \%$ and 0.175 seconds, respectively.
\end{abstract}

\section{Keywords}

Genetic algorithm, photovoltaic, PID controller

\section{INTRODUCTION}

The study of renewable energy sources has been an inclusive concern to the world, and has taken the attention of many institutions like the European Commission and others. Renewable energy is a clean energy system that has no effect during or after generation on the environment and this took the attention of researchers to make continuous improvement in solar energy. Renewable energy is numerous, free, sustainable, and can be utilized from different origins such as wind, solar, tidal, hydro, geothermal and biomass

Solar energy could be one of the important sources as a substitution energy for the hereafter. There are two kinds of technology that anticipated solar energy, solar thermal and solar cells. A PV cell (solar cell) transforms the sunlight into the electrical energy by the photovoltaic effect.

Energy from PV exhibits various advantages, such as, it needs little maintenance and produces no environmental pollution. PV module presents the fundamental power conversion unit of a PV generator system.

\subsection{Literature survey}

Many papers presented different simulations of PV system. In [1], a procedure for the simulation of photovoltaic modules with MATLAB/Simulink is presented. One-diode equivalent circuit is employed in order to investigate $I-V$ and $P-V$ characteristics of solar module. The final model takes irradiation, operating temperature in Celsius and module voltage as input and gives the output current Ipv and output voltage Vpv. Also in [2] a one-diode equivalent circuit-based versatile simulation model in the form of the masked block PV module is proposed. By the model, it is allowed to estimate the behavior of PV module with respect to changes in irradiance intensity, ambient temperature and parameters of the PV module. In another study presented in [3], a fractionalorder PID (FOPID) controller is designed to control a DC-DC boost converter in a PV-system. In order to obtain the best system performance, parameters of the proposed controller are tuned by using Particle Swarm Optimization (PSO) algorithm. In another paper [4] the effect of uniform and non-uniform irradiance on a series connected solar photovoltaic (PV) array is presented in detail under MATLAB-Simulink environment. The proposed simulation model helps us to investigate the characteristics of a PV array under different irradiance and temperature conditions [4].

Our work in this paper is framed around three major parts. First, an overview of mathematical model of the PV system is summed up. Second, a proportional-integral-derivative (PID) controller is designed to enhance the performance of the system. Finally, in order to obtain the best system performance, parameters of the proposed controller are tuned by using the genetic algorithm. The system response is tested under various solar irradiation and constant temperature. Percentage overshoot $(\mathrm{Mp})$ and rise time $(\mathrm{Tr})$ are measured and compared with other papers. The comparison shows that the system with the PID controller performs better than the system without the controller.

\section{MATHEMATICAL MODEL OF THE PV SYSTEM}

Photovoltaics is the direct conversion of sunlight to electricity. The common abbreviation for photovoltaics is PV. The history of photovoltaics started in 1839, when Becquerel discovered the photo effect.

\subsection{Mathematical model of PV panel}

The first part of the system is the solar cell. Solar cells are in fact large area semiconductor diodes. Due to the photovoltaic effect energy of light (energy of photons) is converted into electrical current. The equivalent circuit for the simplest solar cell consists of a diode and a current source connected in parallel, as shown in figure 1 [5]. The source current is directly proportional to the solar radiation and diode represents the PN junction of a solar cell.

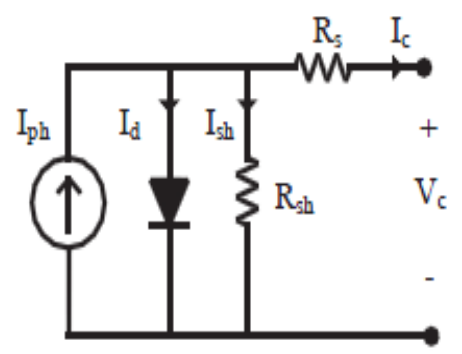

Fig 1 : One Diode Model of PV Cell 
Equation of the load current is:

$I=\left[\left(I_{p h} \times N_{p}\right)-I_{d}-I_{s h}\right]$

Where:

(Iph) is photocurrent (A);

(Id) is diode current;

(Ish) is the current loss because of the shunt resistance;

(Np) the parallel connected PV cell number that effects the module current.

The thermal voltage equation is:

$V_{t}=\frac{k T}{q}$

Where:

(k) is boltzmann constant, $1.38 \times 10-23 \mathrm{~J} / \mathrm{K}$;

(T) is solar cell temperature (K);

(Q) is charge of electron, $1.6 \times 10-19 \mathrm{C}$.

The reverse saturation current equation for the PV system using simulink on MATLAB, as shwon in figure.2, is:

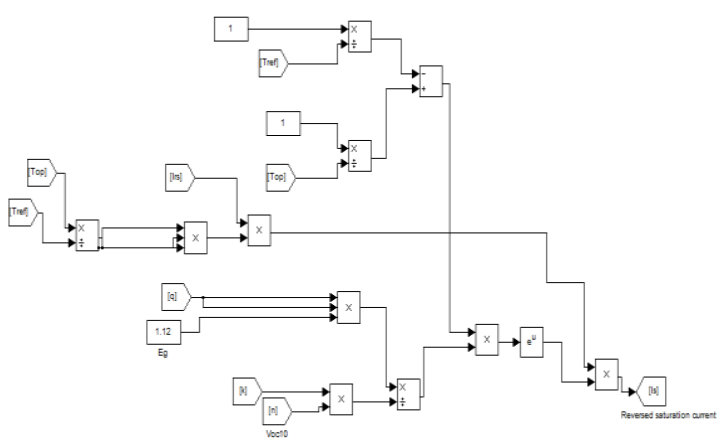

Fig 2 : Reverse Saturation Current

$I_{s}=\left[\left(\frac{1}{T}-\frac{1}{T_{\text {ref }}}\right) \times\left(\left(q^{2} \times E_{g}\right) /(k \times\right.\right.$

neulrsTTref3(3)

where:

(T) the temperature of the PV panel;

$\left(\mathrm{T}_{\mathrm{ref}}\right)$ the refrence temperature of the PV panel;

The reverse saturation current in the above equation for our PV system using Simulink on MATLAB, as described in figure. 3 , is:

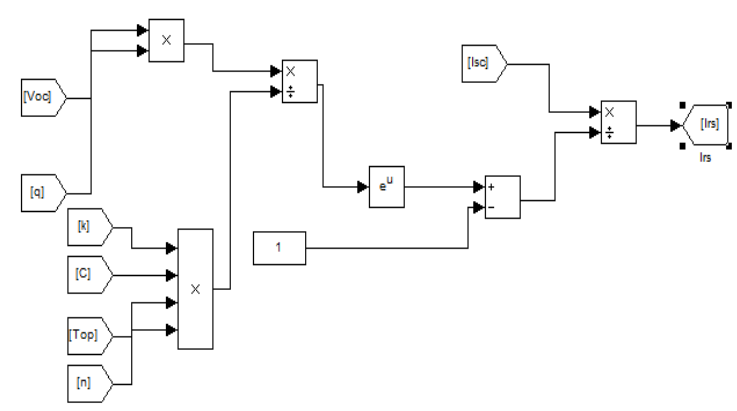

Fig 3 : Reverse Saturation Current at the above Equation

$I_{r s}=\left[\left(V_{o c} * q\right) /(K * c * T * n)\right]\left[I_{s c} /\left(e^{u}-1\right)\right]$

where:

(V) open circuit voltag;

(Isc) short circuit current.

Shunt current equation:

$I_{s h}=(V+I R) / R_{p}$

where:

(Ish) shunt current;

(Rs) the series resistance of the PV panel;

(Rp) the parallel resistance of the PV panel.

Diode current equation for our PV system is described in figure.4, as presented using Simulink on MATLAB, is:

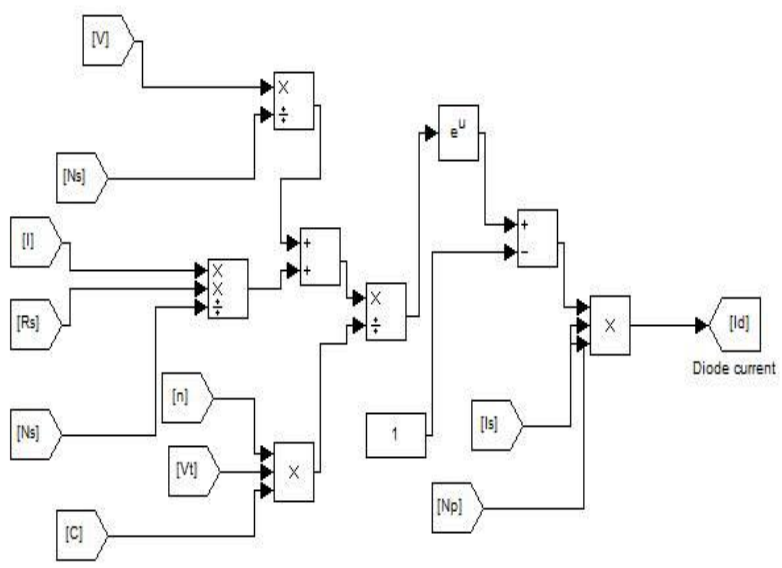

Fig 4 : Diode Current

$I_{d}=\left[\left[\left(V / N_{s}\right)+\left(I * R_{s} / N_{s}\right)\right] /\left[n * V_{t} *\right.\right.$

$c e u-1 * I s * N p(6)$

where:

$\left(\mathrm{I}_{\mathrm{d}}\right)$ diode current;

$\left(\mathrm{N}_{\mathrm{s}}\right)$ the series connected PV cell number that effects module 
voltage;

$\left(\mathrm{V}_{\mathrm{t}}\right)$ thermal voltage;

phase current equation:

$I_{p h}=\left[\left(\left(T-T_{r e f}\right) * K\right)+I_{s c}\right] * I_{r r}(7)$

where:

$\left(\mathrm{I}_{\mathrm{rr}}\right)$ irradiation.

\subsection{Converter Model}

The second part of the system is the converter. A boost DCDC converter is used as a power electronic interface between the load and PV panels in the P-V system. The converter is a powerful electronic device used to produce a higher regulated output voltage from a lower unregulated input voltage [3]. The circuit of the converter consist of an inductor $\mathrm{L}$, a power switch $\mathrm{S}$, a diode, $\mathrm{D}$, a filter capacitor $\mathrm{C}$ and a load resistor $\mathrm{R}$, as shown in figure 5 [3].

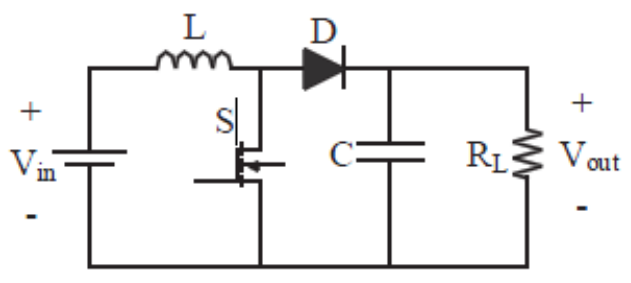

Fig 5 : Boost Converter Circuit

The working principle of the converter is cleared as follows: When the switch is ON mode, the diode is reverse biased (OFF). In this mode, inductor directly connected to the input voltage source and stores energy. Meanwhile, the load is powered by the capacitor. When the switch is OFF mode, the diode is forward biased $(\mathrm{ON})$. In this mode, both stored energy of the inductor and input voltage source supply power to the load. The capacitor and the inductor values of the converter are calculated respectively by using the formulas [5]:

$C_{\text {min }}=\frac{D I_{\text {out }(\max )}}{f_{s} \Delta V_{\text {out }}}$

$L_{\text {min }}=\frac{\left(V_{\text {out }}-V_{\text {in }}\right) V_{\text {in }}}{\Delta I_{L} f_{s} V_{\text {out }}}$

Where:

$\left(\mathrm{C}_{\min }\right)$ and $\left(\mathrm{L}_{\min }\right)$ are the minimum capacitor and inductor values;

$\left(\mathrm{V}_{\text {in }}\right)$ and $\left(\mathrm{V}_{\text {out }}\right)$ are the input and output voltage of the converter;

$\left(\mathrm{f}_{\mathrm{s}}\right)$ is the switching frequency;

$\left(\Delta \mathrm{V}_{\text {out }}\right)$ is the output voltage ripple;

$(\Delta \mathrm{IL})$ is the inductor current ripple;

(D) is the duty cycle, which is the ratio between the pulse duration and period of a rectangular waveform.

\subsection{PID Controller}

The third part in the system is the controller. The controller is used to control the converter in the PV system. There are numerous controllers that can be used to control dynamic systems like the PV systems. In this paper Proportional-
Integral-Derivative (PID) controller is used. Many algorithms can be used to tune the parameters of the controller, such as Genetic algorithms (GA) [6], Differential Evolution (DE) algorithm [7] and PSO algorithm [8]. In this paper genetic algorithm will be used, as will be explained later in the algorithm. Many papers used Fractional Order Proportional Integral Derivative controller (FOPID) instead of PID but FOPID is more complex because it has five parameters to be selected, whereas classical PID has three parameters only, which implies that tuning of the parameters of the FOPID controller is more complex. In this paper the PID controller supported the designed model of the PV system.

The memorial PID refers to the first letters of the names of the terms that industrialize the three-term controller: $(\mathrm{P})$ for the proportional term, (I) for the integral term and (D) for the derivative term. PID controllers are the most quite used industrial controllers. The theoretical basis for analyzing the performance of PID control is frequently helped by the simple representation of an Integrator by the Laplace transform, [1/s], while a differentiator uses [s]. The PID controller has three different representations [9] displayed in figure 6. First, there is a nominal representation (Figure 6.1(a)), where each of the three terms can be selected to achieve different control actions. Secondly, there is a time domain operator (Figure 6.1(b)), and finally, there is a Laplace transform version of the PID controller (Figure 6.1(c)).

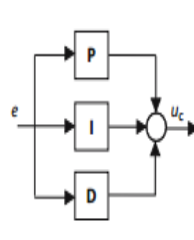

(a)

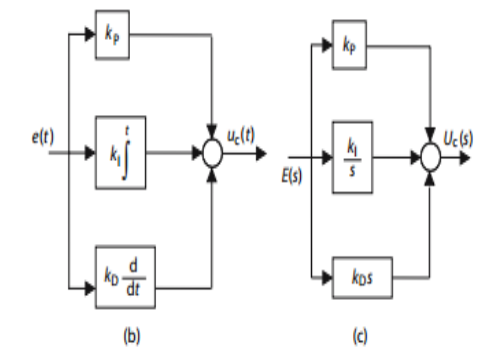

Fig 6 : PID Controller Representation

Where

(e) , (uc) are the Symbolic forms;

$(\mathrm{e}(\mathrm{t})),(\mathrm{uc}(\mathrm{t}))$ are the Time Domain forms;

$(\mathrm{E}(\mathrm{s})),(\mathrm{Uc}(\mathrm{s}))$ are the Laplace domain forms;

$\left(\mathrm{k}_{\mathrm{p}}\right)$ Proportional gain;

$\left(\mathrm{k}_{\mathrm{i}}\right)$ Integral gain;

$\left(\mathrm{k}_{\mathrm{D}}\right)$ Derivative gain.

The equation of the PID controller is given by [9]:

Time domain form: $u_{c}(t)=k_{p} e(t)+k_{i} \int_{0}^{t} e(\tau) d \tau+k_{d}$

Laplace domain form: $\quad U_{c}(\mathrm{~s})=\left[\mathrm{k}_{\mathrm{p}}+\frac{\mathrm{k}_{\mathrm{i}}}{\mathrm{s}}+\mathrm{s} \mathrm{k}_{\mathrm{D}}\right] \mathrm{E}(\mathrm{s})$

\section{GENETIC ALGORITHM}

The genetic algorithm (GA) is an optimization and search technique based on the principle of genetic and natural selection. A GA allows a population composed of many individuals to evolve under specified selection rules to a state, minimizing the fitness function (i.e., minimizing the cost 
function). Fig 7 present the flowchart of the genetic algorithm. The fitness function of this proplem is minimizing the maximum overshoot and rise time. The values of the GA parameters of the used genetic algorithim are:

$\begin{array}{ll}\text { GEN }=1 \mathrm{e} ; & \text { Maximum number of generation. } \\ \mathrm{POP}=20 ; & \text { Population. }\end{array}$

PCROSS $=0.7 ; \quad$ Crossover Probability.

PMUT $=0.5 ; \quad$ Mutation probability.

Iter $=30 ; \quad$ Number of Iterations.

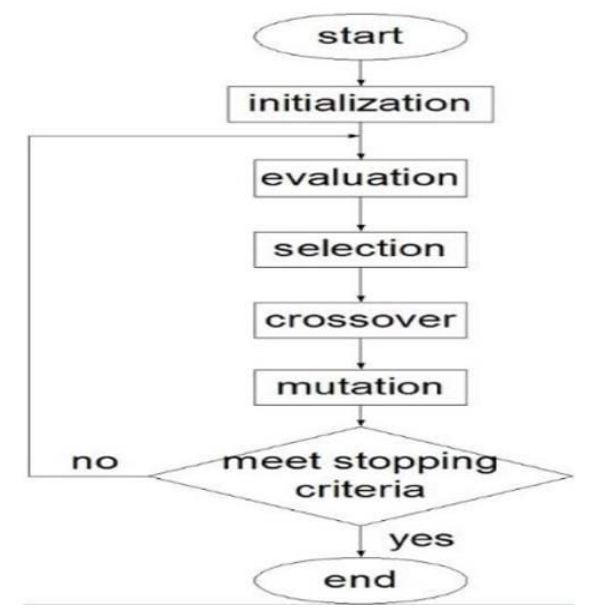

Fig 7 : Flowchart of the genetic algorithm

\section{DISCUSSION AND RESULTS}

In this paper, GA is used to find the optimum parameters for PID controller which minimizes the maximum overshoot and the rise time. Thereby; a PID is merged with the PV system in figure 8 presented using MATLAB/Simulink. The PV panel in figure 8 includes all the mathematical model illustrated in the previous section. The population consists of 20 chromosomes, each chromosome contains 3 genes and each gene represents $\mathrm{P}$, I and D respectively. The minimum fitness function which represents the minimum overshoot and rise time is presented in figure 8 . In figure 9 , the minimum value settled after the 20th iterations, fig.9(a) for 5 iterations, fig.9(b) for 10 iterations and fig.9(c) for 20 iterations. The corresponding chromosome which satisfy the minimum functions are $\mathrm{P}=1.7130, \mathrm{I}=3.8$ and $\mathrm{D}=0.001$. Those $\mathrm{P}, \mathrm{I}$ and $\mathrm{D}$ value lead to maximum overshoot of $0.1 \%$ and rise time of 0.175 seconds. In comparison to [3], this work reduced the overshoot with $0.7 \%$ and rising time 0.545 seconds.

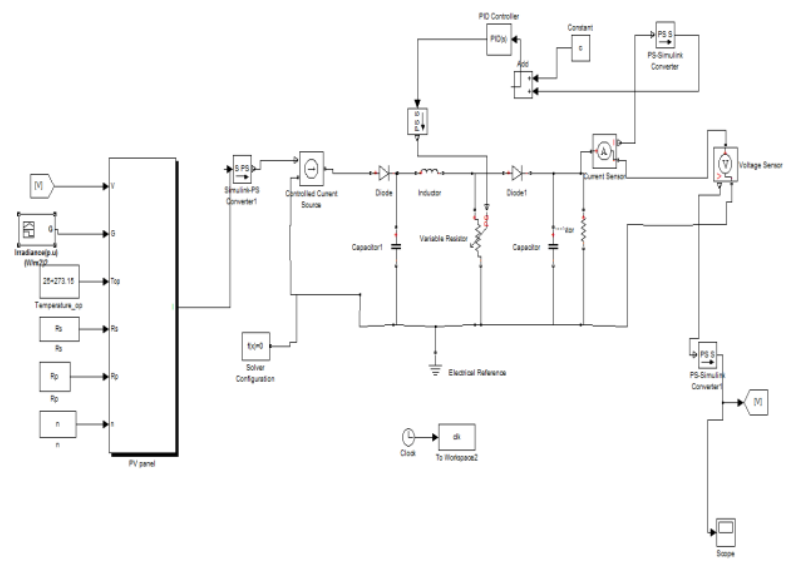

Fig 8 : PV system architecture on Simulink/ MATLAB

The irradiation is constant with $800 \mathrm{~W} / \mathrm{m}^{2}$ for 10 seconds. Figure 10 shows the output voltage versus the time and the maximum overshot almost is zero. Table 1 compares between our work and the work done in [3]. In this paper the maximum over shoot and rise time are reduced by $0.7 \%$ and 0.6 seconds, respectively. This approach doesn't require a complex circuit such as FOPID or extra hardware implementation. Finally, table 2 shows the PV system paramters.

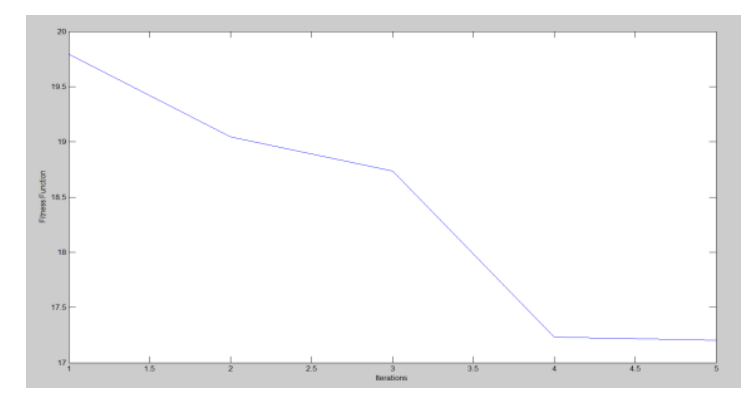

(a)

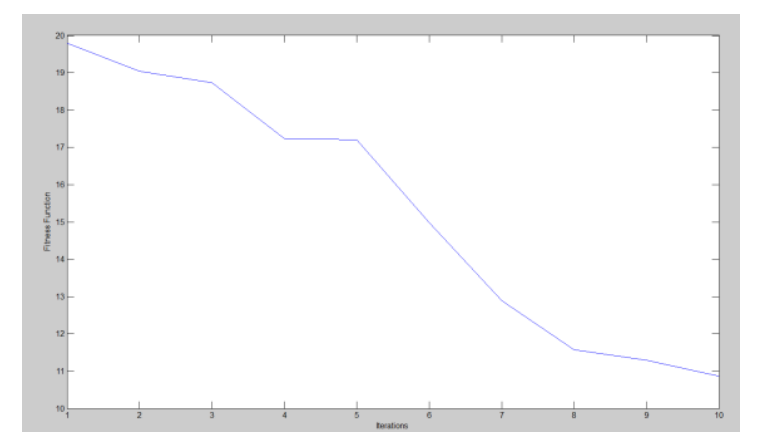

(b) 


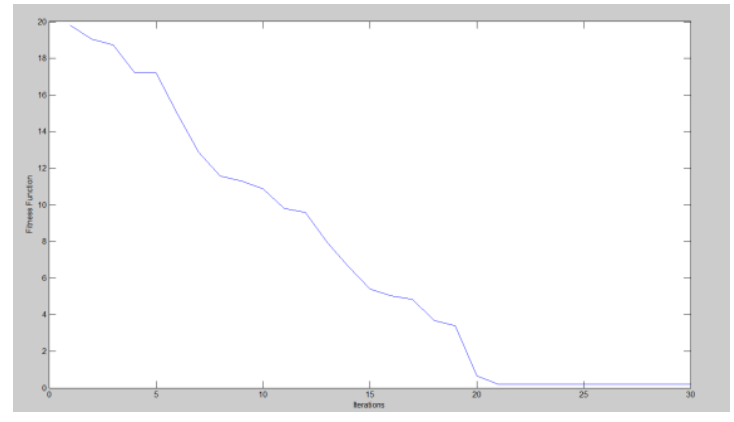

(c)

Fig. 9 : GA iterations versus fitness function for: a) 5 iterations, b) 10 iterations, c) 20 Iterations

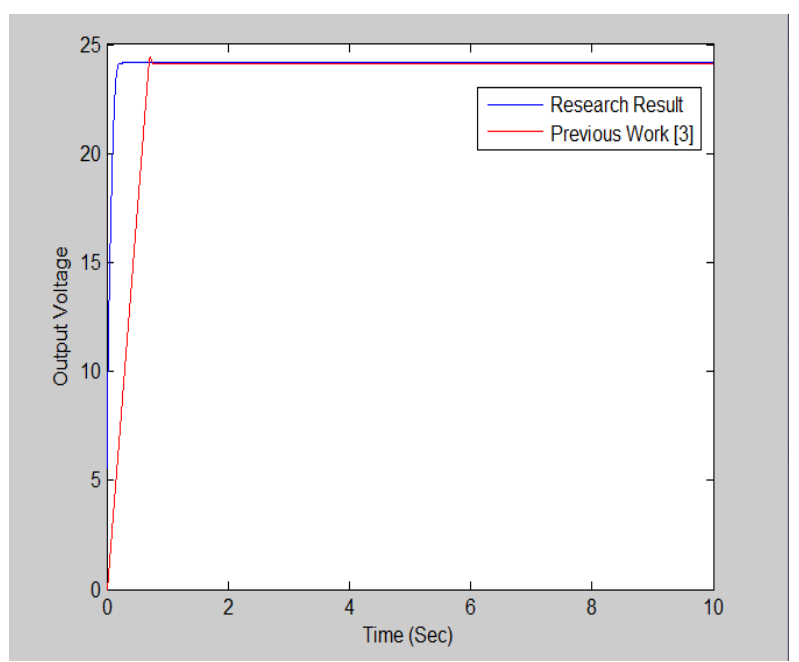

Fig 10 : Output voltage versus time.

Table 1. Parameters of PV system

\begin{tabular}{|c|c|}
\hline Parameters of Boost Converter & \multicolumn{1}{|c|}{$20 \mathrm{kHz}$} \\
\hline Sampling frequency (Ts) & $5 \mathrm{kHz}$ \\
\hline Switching frequency (fs) & $24 \mathrm{~V}$ \\
\hline Output voltage (VO) & $5 \%$ \\
\hline $\begin{array}{c}\text { Max. output voltage ripple } \\
(\mathrm{VC})\end{array}$ & $5 \%$ \\
\hline Max. input current ripple $(\Delta \mathrm{I})$ & $6.8 \mathrm{mF}$ \\
\hline Input Capacitor (Cin) & $11.5 \mathrm{mF}$ \\
\hline Output Capacitor (Cout) & $1.25 \mathrm{mH}$ \\
\hline Inductor (L) & $12.5-25-50 \mathrm{Ohm}$ \\
\hline Load (R) & \\
\hline PV panel Parameters & 1 \\
\hline Nsc & 5 \\
\hline Npc & $17 \mathrm{~V}$ \\
\hline Vr & $3 \mathrm{~A}$ \\
\hline Ir & \\
\hline & \\
\hline & \\
\hline & \\
\hline & \\
\hline
\end{tabular}

\begin{tabular}{|c|c|}
\hline$\alpha$ & $3.10-3 \mathrm{~mA} / \mathrm{oC}$ \\
\hline$\beta$ & $-73.10-3 \mathrm{~mW} / \mathrm{oC}$ \\
\hline Isc & 3.5 \\
\hline $\mathrm{Gr}$ & $1000 \mathrm{~W} / \mathrm{m} 2$ \\
\hline Tcr & $25 \mathrm{oC}$ \\
\hline
\end{tabular}

Table2. Comparison between this work and previous work [3]

\begin{tabular}{|c|c|c|}
\hline Parameters & This work & {$[3]$} \\
\hline $\mathrm{M}_{\mathrm{p}}$ & 0.1 & 0.8 \\
\hline $\mathrm{T}_{\mathrm{r}}$ & 0.175 & 0.72 \\
\hline $\mathrm{P}$ & 1.7130 & 19.22 \\
\hline $\mathrm{I}$ & 3.8 & 8.32 \\
\hline $\mathrm{D}$ & 0.001 & 0.056 \\
\hline
\end{tabular}

\section{CONCLUSION}

PV system is one of vital renewable energy in our word. Thereby; researchers made a lot of research on PV panels to enhance its performance. This paper introduces a mathematical model for PV system with PID controller. The PID controller is used to enhance the output of PV system. The GA is used to reach the optimum values of PID controller parameters which lead to minimum overshoot and minimum rise time in output voltage. The overshoot is reduced to $0.1 \%$ and the rise time is set to 0.175 seconds. The results show that PID controller has a better response compared with FOPID controller. For the future work particle swarm optimization (PSO) can be used instead of GA. Furthermore, neural network can be placed instead of PID controller which reduce the hardware of the system which leads to minimum the complexity.

\section{REFERENCES}

[1] Pandiarajan, N.; Muthu, Ranganath. Mathematical modeling of photovoltaic module with Simulink. In: Proceeding of International Conference on Electrical Energy System. 2011. pp. 3 -5.

[2] Qi, Chen; Ming, Zhu. Photovoltaic module Simulink model for a stand-alone PV system. physics procedia, 2012, 24: pp. $94-100$.

[3] Sahin, Erol; Ayas, Mustafa Sinasi; Altas, Ismail Hakki. A PSO optimized fractional-order PID controller for a PV system with DC-DC boost converter. In:Power Electronics and Motion Control Conference and Exposition (PEMC), 2014 16th International. IEEE, 2014. pp. 477 - 481.

[4] Chowdhury, Ahmed Sony Kamal; Salam, K. M. A.; Razzak, M. Abdur. Modeling of MATLAB-Simulink based photovoltaic module using flyback converter. In: Strategic Technology (IFOST), 2014 9th International Forum on. IEEE, 2014. pp. 378 - 381.

[5] Brigitte Hauke, "Low power DC-DC application/Basic calculation of a boost converter's power stage", Texas Instrument application report, July, 2010.

[6] L.Y. Chang, H.C. Chen, "Tuning of fractional PID controllers using adaptive genetic algorithm for active 
magnetic bearing system", WSEAS Transactions on Systems, Vol. 8, 2009, pp. 226-236.

[7] A. Biswas, S. Das, A. Abraham, S. Dasgupta, "Design of fractionalorder $\mathrm{P} I \lambda \mathrm{D} \mu$ controllers with an improved differential evolution", Engineering Applications of Artificial Intelligence, Vol. 22, 2009, pp. 343- 350.

[8] M. Zamania, M. Karimi-Ghartemanib, N. Sadatib, M. Parnianib," "Design of a fractional order PID controller for an AVR using particle swarm ptimization", Control Engineering Practice, Vol. 17, 2009, pp. 1380-1387.

[9] Johnson, Michael A., and Mohammad H. Moradi. PID control. Springer-Verlag London Limited, 2005.

[10] Haupt Randy L., Haupt Sue Ellen, "Practical Genetic Algorithms" Second Edition, 2004, pp.189-190. 